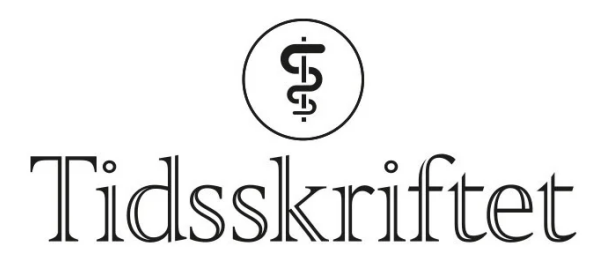

DEN NORSKE LEGEFORENING

\title{
Hva består oksymetriparametrene på blodgassutskriften av?
}

FRA LABORATORIET

\section{ERIK WILHELM VINNES}

erik.wilhelm.vinnes@helse-bergen.no

Erik Wilhelm Vinnes er spesialist i medisinsk biokjemi, overlege ved Avdeling for medisinsk biokjemi og farmakologi, Haukeland universitetssjukehus, og universitetslektor ved Klinisk institutt 2, Universitetet i Bergen.

Forfatteren har fylt ut ICMJE-skjemaet og oppgir ingen interessekonflikter.

\section{GUNHILD HOLMAAS}

Gunhild Holmaas er spesialist i anestesiologi med subspesialitet i intensivmedisin og overlege ved Intensivmedisinsk seksjon, Kirurgisk serviceklinikk, Haukeland universitetssjukehus.

Forfatteren har fylt ut ICMJE-skjemaet og oppgir ingen interessekonflikter.

Oksymetriparametrene på blodgassutskriften måles med en egen spektrofotometrisk modul som inkluderer måling av hemoglobin samt de klinisk mest relevante hemoglobinderivatene. Men hva er disse derivatene, og hvilken informasjon gir oksymetriparametrene oss?

Analysene på en blodgassutskrift deles typisk inn i kategoriene blodgass-/syre-base-verdier, oksymetriverdier, elektrolyttverdier, metabolittverdier og beregnede verdier (figur 1). I dette innlegget ønsker vi å presentere parametrene som inngår under oksymetridelen av utskriften. De generelle prinsippene for blodgassmåling er godt standardisert på moderne blodgassinstrument, men det bemerkes at detaljene i utskriftsoppsettet kan variere noe avhengig av produsent og lokale tradisjoner. 
Blodgassverdier

\begin{tabular}{|c|c|c|c|c|}
\hline$\downarrow \mathrm{pH}$ & 7,329 & & {$[7,360$} & $-7,440$ \\
\hline$\uparrow \mathrm{pCO}_{2}$ & 7,25 & $\mathrm{kPa}$ & 4,50 & $-6,10$ \\
\hline$c$ Base $(\text { Ecf })_{C}$ & 2,4 & $\mathrm{mmol} / \mathrm{L}$ & $-3,0$ & $-3,0$ \\
\hline$\uparrow \mathrm{cHCO}_{3}{ }^{-}(\mathrm{P})_{c}$ & 27,8 & $\mathrm{mmol} / \mathrm{L}$ & l 22,0 & $-26,0$ \\
\hline$\downarrow p \mathrm{O}_{2}$ & 9,84 & $\mathrm{kPa}$ & l 11,0 & $-13,0$ \\
\hline
\end{tabular}

Oksimetriverdier

$\begin{array}{lcl}\mathrm{ctHb} & 12,6 * & \mathrm{~g} / \mathrm{dL} \\ \mathrm{sO}_{2} & 93,1 & \% \\ \mathrm{FO}_{2} \mathrm{Hb} & 90,6 & \% \\ \mathrm{FCOHb} & 1,5 * & \% \\ \mathrm{FHHb} & 6,7 & \% \\ \mathrm{FMetHb} & 1,2 & \%\end{array}$

Elektrolyttverdier

$+\mathrm{cNa}^{+}$

$\mathrm{cK}^{+}$

134 * $\mathrm{mmol} / \mathrm{L}$

$137-145$

4,2 * $\mathrm{mmol} / \mathrm{L}$

$3,5-5,0$

$\downarrow \mathrm{cCl}^{-}$

$\mathrm{CCa}^{2+}$

97 * $\mathrm{mmol} / \mathrm{L}$

$98-109$

$1,11 \mathrm{mmol} / \mathrm{L}$

$c \mathrm{Ca}^{2+}(7.4)_{c}$

Metabolittverdier

$1,07 \mathrm{mmol} / \mathrm{L}$

$\uparrow$ cGlu

$6,6^{*} \mathrm{mmol} / \mathrm{L}$

I

$4,0-6,0 \quad]$

$\uparrow$ cLac

Beregnede verdier

$2,1 \mathrm{mmol} / \mathrm{L} \quad\left[\begin{array}{ccc}0,4 & -1,3\end{array}\right]$

Anion gap, $\mathrm{K}^{+} \mathrm{C}$

$13,3 \mathrm{mmol} / \mathrm{L}$

$5,0-21,0 \quad]$

Oksygenstatus
$\mathrm{pO}_{2}(\mathrm{a}) / \mathrm{FO}_{2}(\mathrm{I})_{C}$
46,9 $\mathrm{kPa}$
$\mathrm{p} 5 \mathrm{C}_{\mathrm{C}}$
$3,94 \mathrm{kPa}$

Figur 1 Eksempel på utskrift fra et ABL-blodgassinstrument (Radiometer Medical, Danmark).

\section{Oksymetriparametrene}

Oksymetriparametrene inkluderer total hemoglobin (tHb) og oksygenmetning $\left(\mathrm{sO}_{2}\right)$ samt de fire klinisk mest relevante hemoglobinderivatene: oksyhemoglobin $\left(\mathrm{O}_{2} \mathrm{Hb}\right)$, deoksyhemoglobin ( $\mathrm{HHb}$ ), karboksyhemoglobin (COHb) og methemoglobin (MetHb) (figur 1). Hemoglobinderivater er endrede former av hemoglobin. COHb dannes ved eksponering for karbonmonoksid, som bl.a. kan finnes i røyk og eksos, og MetHb oppstår når $\mathrm{Fe}^{2+}$ erstattes med $\mathrm{Fe}^{3+} \mathrm{i}$ forbindelse med en avvikende oksidasjonsprosess (ㅅ). Både $\mathrm{COHb}$ og MetHb har betydelig nedsatt oksygenbærende evne, noe som resulterer i nedsatt vevsoksygeneringstilbud.

Prefikset $F$ (av eng. fractional) betyr at parameteren er uttrykt som en andel av total hemoglobin (tHb) definert som summen av de fire målte $\mathrm{Hb}$-delene $\mathrm{FO}_{2} \mathrm{Hb}, \mathrm{FHHb}, \mathrm{FCOHb}$ og FMetHb (2 $)$. Dersom man summerer disse, skal man derfor alltid ende opp med $100 \%$.

\section{Funksjonell og fraksjonell oksygenmetning}


$\mathrm{sO}_{2}$ er den funksjonelle oksygenmetningen og er definert som $\mathrm{O}_{2} \mathrm{Hb} /\left(\mathrm{O}_{2} \mathrm{Hb}+\mathrm{HHb}\right)$, der nevneren består av funksjonell hemoglobin med oksygenbærende evne (oksyhemoglobin og deoksyhemoglobin). Et viktig poeng å merke seg er at $s_{2} \mathrm{O}_{2} \mathrm{ikke}$ er det samme som den såkalte fraksjonelle oksygenmetningen $\left(\mathrm{FO}_{2} \mathrm{Hb}\right)$, der sistnevnte er andel oksyhemoglobin av total hemoglobin, $\mathrm{O}_{2} \mathrm{Hb} /\left(\mathrm{O}_{2} \mathrm{Hb}+\mathrm{HHb}+\mathrm{COHb}+\mathrm{MetHb}\right)(\underline{2})$.

Hos friske vil verdiene være relativt like ettersom man vanligvis har lite sirkulerende dyshemoglobiner (COHb og MetHb). sO $\mathrm{O}_{2}$ vil imidlertid alltid være noe høyere enn $\mathrm{FO}_{2} \mathrm{Hb}$ fordi det alltid foreligger en liten andel sirkulerende COHb og MetHb (ca. $2 \%$ ). Ved tilstedeværelse av større konsentrasjoner av $\mathrm{COHb}$ eller MetHb vil man derfor kunne få en «normal» $\mathrm{SO}_{2}$ selv om pasientens oksygenbærende evne åpenbart er betydelig redusert. Ved slike tilfeller er det viktig å være klar over at $\mathrm{FO}_{2} \mathrm{Hb}$ bedre representerer hemoglobinets faktiske oksygenbærende evne.

\section{Måleprinsipp}

Oksymetriparametrene måles på moderne blodgassinstrumenter med en egen spektrofotometrisk modul der prinsippet for målingen er gjennomlysning med lys med spesifikke bølgelengder mellom 478 og $672 \mathrm{~nm}(\underline{2})$. De forskjellige hemoglobinderivatene har sine distinkte absorpsjonsspektre, og det er på grunnlag av disse at instrumentet kan kvantitere andelen av hver av de fire hemoglobinderivatene. Et alminnelig portabelt pulsoksymeter med fingerprobe benytter samme måleprinsipp, men da med lys med to bølgelengder, 66o nm (rødt) og $940 \mathrm{~nm}$ (infrarødt), for å estimere den perifere oksygenmetningen i kapillært arterieblod $\left(s_{p} \mathrm{O}_{2}\right)$. Slik ikke-invasiv måling benyttes hyppig i det daglige, men har en rekke begrensninger som det er viktig å være klar over (3).

Som nevnt innledningsvis kan det forekomme lokale variasjoner i valg av utrapporterte parametre og enheter ettersom det er opp til hvert laboratorium å stille inn oppsettet på instrumentet. Dersom det er noe man savner eller ønsker endret, anbefales det at man kontakter laboratoriet.

\section{LITTERATUR}

1. Solheim L, Brun AC, Greibrokk TS et al. Methemoglobinemi - årsaker, diagnostikk og behandling. Tidsskr Nor Lægeforen 2000; 120: 1549-51. [PubMed]

2. Radiometer Medical. ABL8oo Flex reference manual. 2012.

3. Chan ED, Chan MM, Chan MM. Pulse oximetry: understanding its basic principles facilitates appreciation of its limitations. Respir Med 2013;107: 789-99. [PubMed][CrossRef]

Publisert: 10. februar 2022. Tidsskr Nor Legeforen. DOI: 10.4045/tidsskr.21.0855

(C) Tidsskrift for Den norske legeforening 2023. Lastet ned fra tidsskriftet.no 26. april 2023. 